\title{
Uncertainty and the orientation reaction '
}

\author{
D. E. BERLYNE AND DONMA M. BORSA
}

UNIVERSITY OF TORONTO

In Experiment 1, blurred pictures evoked longer desynchronization than clear pictures but not more intense GSRs. Experiment 2 confirmed that the EEG effect depended on subjective uncertainty by showing that it did not occur when a blurred picture was immediately preceded by a clear version of the same picture.

When a display is photographed out of focus, objective uncertainty (i.e., the uncertainty associated with the sample space of clear photographs to which the blurred photograph might correspond) increases with blur (Meyer-Eppler, 1959). Nicki (1967) has shown, however, that subjective uncertainty (derived from the number of hypotheses regarding the object depicted and the relative confidence placed in each) reaches a peak with an intermediate degree of blur. He also found that the replacement of a blurred picture with its corresponding clear picture would reinforce an instrumental response in human Ss. That this reward value depends on removal of subjective uncertainty is attested by the finding that it occurred only with the degree of blur associated with maximum subjective uncertainty and the finding that the effect disappeared when uncertainty with respect to the object depicted was removed by displaying a clear version of the picture Immediately before the blurred version.

According to hypotheses presented elsewhere (Berlyne, 1960, 1963, 1966), ambiguous stimull, such as blurred pictures, induce "perceptual curiosity," conceived as a condition of heightened arousal or drive, whose alleviation through incoming information is rewarding. Perceptual curiosity is held to result from subjective uncertainty, which is regarded as a form of conflict (competition among response tendencies corresponding to alternative hypotheses). Previous experiments (Berlyne, 1961) showed that one component of the orientation reaction or index of heightened arousal, namely, GSR, is intensified by conflict between motor or verbal response tendencies. The two experiments to be reported tested the assumption that subjective uncertainty resulting from exposure to a blurred picture will likewise intensify the orientation reaction, which would mean that this variable conduces to heightened arousal. Subjective uncertainty was induced through blurring, and the duration of EEG desynchronization was used as an index of the intensity of the orientation reaction. In the first experiment, GSR was also recorded.

\section{EXPERIMENT 1}

\section{Subjects}

Data from $10 \mathrm{Ss}$, all male undergraduates taking elementary psychology courses, were analyzed.

\section{Stimulus Material}

Two sequences of 30 colored slides, all depicting common objects on plain backgrounds, were prepared. In sequence $\mathrm{A}, 15$ of the slides were clear and 15 blurred. They were arranged in a random order, with the restriction that each consecutive set of six contained three clear and three blurred items. Sequence $B$ was formed by replacing each clear slide in Sequence $A$ with a blurred version of the same picture and vice versa. Five Ss were exposed to Sequence $A$ and five to Sequence $B$.

Each blurred slide was produced by projecting the corresponding clear slide from a Kodak Carousel Model 550 projector, located $11 \mathrm{ft}$ from the screen, with the far end of the lens casing $31.4 \mathrm{~mm}$ from the flange (as compared with $13.7 \mathrm{~mm}$ for projection in focus). The blurred image on the screen was photographed with a camera $7 \mathrm{ft}$ away from the screen. This degree of blur approximated the degree found by Nicki (1967) to induce maximum subjective uncertainty for nonchromatic slides (projector $13 \mathrm{ft} 8 \mathrm{in}$. from screen, lens casing projecting $28 \mathrm{~mm}$ from flange).

\section{Measuring techniques}

A Grass Model 5 polygraph recorded EEG from a silver-disc electrode placed over the right occipital lobe, with a clip attached to the right ear lobe as ground, and GSR from Fels mercury-coated zinc electrodes placed on the two palms. Recording techniques, criteria for discarding Ss, and methods for scoring responses were identical with those used in previous experiments (Berlyne, Craw, Salapatek \& Lewis, 1963; Berlyne \& McDonnell, 1965).

\section{Procedure}

The $S$ was seated in an easy chair in a darkened, shielded compartment facing a screen. He was told simply to look at the pictures that would appear on the screen and assured that no questions would be asked about the pictures later.

The appropriate sequence was then projected. Each picture appeared on the screen for 4 sec. The interstimulus interval varied between $2 \mathrm{sec}$ and $30 \mathrm{sec}$. E waited until alpha waves had reappeared before manually triggering the Hunter timer to expose the next slide. 


\section{Results}

The mean durations of desynchronization were 7.34 sec for blurred pictures and $6.68 \mathrm{sec}$ for clear pictures $(F=4.33$, df $=1 / 272, p<.05)$.

As regards GSR, log-conductance-change scores (Haggard, 1949) for blurred and clear slides were not significantly different.

Since various components of the orientation action have been to be found to increase with intensity (see Berlyne, 1960), the possibility that the blurred pictures evoked longer desynchronization because of greater illuminance was investigated. A Weston Master IV (model 745) selenium light meter was used to take readings from five regions of the projected image from each slide, viz., the four corners and the central region. The means were $0.135 \mathrm{ft}-\mathrm{c}$ for the blurred slides and $0.234 \mathrm{ft}-\mathrm{c}$ for the clear slides. The total was higher with the clear version than with the blurred version in the case of 27 slides out of 30 , with one tie, so that $p<.01$ according to the sign test. The difference in illuminance was therefore significant in a direction contrary to the hypothesis under investigation.

In order to verify that the difference in EEG scores was due to subjective uncertainty and not to blur as such, it was necessary to compare the effects of blurred and clear pictures in conditions separating uncertainty from blur. This could be done by presenting a clear version of the same picture immediately before each blurred picture, so that $S$ would know what object was depicted while the blurred picture was exposed (cf., Mackworth \& Bruner, 1966). This method was used in Experiment 2.

\section{EXPERIMENT 2}

\section{Subjects}

EEG data from 30 male undergraduates, taking summer session courses in psychology, were analyzed.

\section{Stimulus Material}

Every $S$ was exposed in turn to two sequences of 16 slides, each comprising eight clear pictures and blurred versions of the same eight pictures. In the B-C condition, the blurred version of each picture came immediately before the clear version of the same picture. In the C-B condition, the clear version came immediately before the blurred version. Half of the $\mathrm{Ss}$ went through Sequence 1 in the $\mathrm{B}-\mathrm{C}$ condition and then through Sequence 2 in $\mathrm{C}-\mathrm{B}$ condition, while the remaining half had the C-B condition in Sequence 1 and then the B-C condition in Sequence 2. The slides were taken from among those used in Experiment 1 .

\section{Procedure}

Immediately before either sequence, $S$ was told how the sequence to be presented was constructed, i.e., that he would see a blurred picture followed by the corresponding clear picture or that he would see a clear picture followed by the corresponding blurred picture. Otherwise, the procedure for recording and scoring the EEG measures was exactly as in Experiment 1 .

\section{Results}

Table 1 shows the mean desynchronization durations for blurred and clear slides in B-C and C-B conditions Sequence 1 and Sequence 2 separately and over both sequences.

It will be seen that, when a blurred picture preceded the corresponding clear picture, it evoked longer desynchronization in both sequences. When it followed the corresponding clear picture, it evoked shorter desynchronization in sequence 1 and desynchronization of comparable duration in Sequence 2. The effect of primary interest, namely, the interaction between B$\mathrm{C} / \mathrm{C}-\mathrm{B}$ conditions and blur/clarity was significant ( $F<17.96$, df $<1 / 921, p<.001)$. The triple interaction of these two variables with Sequence 1 /Sequence 2 was also significant ( $F=5.07, d f=1 / 921, p<.025)$.

The results thus confirmed the prediction. But one additional possibility needs to be examined. Desynchronization was longer in response to blurred slides in the B-C condition and to clear slides in the C-B condition. In both conditions, the mean score was thus higher for the slides occupying odd-numbered temporal positions. Since components of the orientation reaction, including desynchronization duration, tend to habituate as a sequence of stimuli proceeds and since odd-numbered items appear on the average earlier than even-numbered items, the double interaction might simply reflect differential habituation and have nothing to do with uncertainty. This hypothesis was tested by taking the mean difference between desynchronization durations for odd-numbered and even-numbered stimuli in Sequence 1 of Experiment 2 and comparing it with the corresponding mean difference for the first 16 stimuli in Experiment 1. It will be recalled that, in that experiment, odd-numbered positions were occupied equally often by blurred and clear slides, as were even-numbered positions. So the mean difference derived from Experiment 1 provides an estimate of the effect of oddness vs evenness of temporal position when it is independent of degree of blur. The mean difference in question was equal to +1.246 in Experiment 2 and +0.166 in Experiment $1(t=3.23, d f=38, p<.005)$. So we can conclude that the interaction found in Experiment 2 is not simply a temporal-position effect.

Table 1. Experiment 2. Mean desynchronization duration (in sec)

\begin{tabular}{cccccccc} 
Condition & \multicolumn{2}{c}{$\begin{array}{c}\text { Sequence 1 } \\
\text { Blurred Clear }\end{array}$} & \multicolumn{2}{c}{$\begin{array}{c}\text { Sequence 2 } \\
\text { Blurred Clear }\end{array}$} & \multicolumn{2}{c}{$\begin{array}{c}\text { Both sequences } \\
\text { Blurred Clear }\end{array}$} \\
\hline B-C & 8.04 & 6.58 & 6.95 & 6.33 & 7.50 & 6.46 \\
C.B & 5.96 & 6.97 & 6.85 & 6.90 & 6.40 & 6.94 \\
\hline
\end{tabular}




\section{DISCUSSIOH}

Considering the results of both experiments together, we find evidence that blurred pictures evoke longer desynchronization than clear pictures when they are associated with subjective uncertainty. But they do not do so when they are preceded by corresponding clear pictures and thus robbed of their power to induce subjective uncertainty about their content.

In Sequence 1 of Experiment 2, the blurred slides evoked shorter desynchronization than the clear slides in the $C-B$ condition. When they no longer induced $S$ to wonder what object was depicted, they had a lesser impact. However, they evoked longer desynchroniation, comparable with that evoked by the clear slides, when the C-B condition came in Sequence 2, following experience of the $\mathrm{B}-\mathrm{C}$ condition in Sequence 1 . This is difficult to interpret but presumably represents some kind of perseveration from the association of the blurred pictures with uncertainty and guessing in the earlier sequence.

The failure of the GSR measure, in contrast with the EEG measure, to show an effect of blur in Experiment 1 may possibly have resulted from a lack of sensitivity with regard to this dependent variable. On the other hand, current evidence (see Berlyne, 1967; Lacey, 1967) indicating the separability of 'behavioral" arousal, reflected in autonomic measures, and "cortical" arousal, reflected in EEG measures, might be of some relevance. Subjective uncertainty, calling for "structuring", "organization", or "interpretation" of the stimulus pattern, presumably makes demands on cortical information-processing functions rather than on vegetative functions that facilitate motor activity.

\section{References}

Berlyne, D. E. Conflict, arousal, and curiosity. New York: McGraw-Hill, 1960.

Berlyne, D. E. Conflict and the orientation reaction. J. exp. Psychol., 1961, 62, 476-483.

Berlyne, D. E. Motivational problems raised by exploratory and epistemic behavior. In $\mathbf{S}$. Koch (Ed.), Psychology-a study of a science. Vol. 5. New York: McGraw-Hill, 1963.

Berlyne, D. E. Curiosity and exploration. Science, 1966, 153, 2533.

Berlyne, D. E. Arousal and reinforcement. In D. Levine (Ed.), Nebraska Symposium on Motivation, 1967. Lincoln: University Nebraska Press, 1967.

Berlyne, D, E., Craw, M. A., Salapatek, P. H., \& Lewis, J. L. Novelty, complexity, incongruity, extrinsic motivation, and the GSR. J. exp. Psychol., 1963, 66, 560-567.

Berlyne, D. E., \& McDonnell, P. Effects of stimulus complexity and incongruity on duration of EEG desynchronization. $E E G$ clin. Neurophysiol., 1965, 18, 156-161.

Haggard, E. A. On the application of analysis of variance to GSR data. I, The selection of an appropriate measure. $J$, exp. Psychol., 1949, 39, 378-392.

Lacey, J. I. Somatic response patteming and stress: some revisions of activation theory. In M. H. Appley \& R. Turnbull, (Eds.), Psychological stress: some issues in research. New York: Appleton-Century-Crofts, 1967.

Mackworth, N. H., \& Bruner, J. S. Selecting visual information during recognition by adults and children. Cambridge, Mass.: Harvard Center for Cognitive Studies, 1966.

Meyer-Eppler, W. Grundlagen und Anwendungen der Informations theorie. Berlin: Springer, 1959.

Nicki, R. M. The reinforcing effect of uncertainty reduction on a human operant. Thesis submitted in accordance with requirements for Ph.D. degree, University of Toronto, 1967.

\section{Note}

1. Supported by grants APB-73 from the National Research Council of Canada and $\mathrm{MH}-12528$ from the National Institute of Mental Health, U. S. Public Health Service.

(Accepted for publication October 3, 1967.) 